\title{
The Role of Small Businesses (Small Scale Economic Projects) in Alleviating the Acuity of Unemployment
}

\author{
Haga Elimam ${ }^{1}$ \\ ${ }^{1}$ King Abdulaziz University, KSA \\ Correspondence: Haga Elimam, King Abdulaziz University, KSA. E-mail: helimam@outlook.com
}

Received: January 9, 2017

Accepted: February 3, 2017

Online Published: February 10, 2017

doi:10.5539/ibr.v10n3p120

URL: http://dx.doi.org/10.5539/ibr.v10n3p120

\begin{abstract}
Small businesses are the essential constituents in the development of economy and generating employment opportunities within country. Unemployment is the major concern, which is spreading its roots in various forms and dimensions. The objective of the study was to examine the role of small businesses in alleviating the acuity of unemployment rate. Quantitative approach has been utilized to examine the role of small businesses. Therefore, data was collected from general statistics, directorate of the Kingdom of Saudi Arabia, during the years 2005-2013. Multiple Regression Analysis using the time series approach has been implemented to analyze the gathered information through SPSS version 20.0. The findings have stated that there was a significant impact of small projects on the unemployment rate of Saudi Arabia $(\mathrm{p}=0.097)$. Furthermore, statistically insignificant results were revealed for amount of funding variable $(\mathrm{p}=0.451)$. A negative relationship has been determined between unemployment rate and amount of funding; while positive and direct relationship was determined between unemployment rate and population. Small businesses are vital in escalating the economy of the country and sustaining the environmental protection. However, small businesses must amend themselves according to the strategies devised for large projects to contribute more to alleviate unemployment rate in the Kingdom of Saudi Arabia.
\end{abstract}

Keywords: GDP, labor, small businesses, population, unemployment

\section{Introduction}

Small businesses can be identified as one of the important mechanisms that provides a main share in the economic development of any country (Al-Khatib et al., 2015). The small scale businesses are associated in the globalization, progression of the employment creation, and economic development of the country. The unconstructive effects of economic turndown critically affect the socio-economic circumstances of the individuals (Salem, 2014).

The small business history has turned into the most provocative stories in the economic expansion of the world (Solomon et al., 2013). In an economy, the role of small businesses were supposed to obstruct the economic growth by attracting scarce resources from the larger complements. Community stability, job creation and innovation discovery are included in the global small business contributions. Small businesses employed over sixty million people in 2010 in USA, but many of these corporations have terminated operations; only fifty percent survived for five years (Bressler, Bressler \& Bressler, 2013). Though, small businesses are the builders of many newer organizations, in which many are unprepared for the long-term sustainability (Ji \& Hanna, 2012). Hotels are the second main private employer in USA with around 14 million workers. However, there is a premature closure with the industry related risk in the smaller enterprises (Frazer, 2012).

$80 \%$ of the new jobs are created by the small businesses in the USA with $99.7 \%$ of the firms having less than five hundred employees (Link \& Scott, 2012). Jobs are lost and the community losses the tax paying institution when the small businesses dissolve for any reason. Although, it has been confirmed by the researchers that small businesses tend to collapse before completing 5 years. Limited data is available on the contribution of such factors, which may result in the closure. Therefore, more firms would flourish and survive in case of data presence during first four years (Ji \& Hanna, 2012). A study conducted by Welsh et al., (2014) has revealed that the women in Saudi Arabia are highly educated and gain strong support for being an entrepreneur from their family and friends. Women also rate themselves as successful individuals and have excellent innovative skills. It has been observed that 55\% of the women owned businesses in Saudi Arabia. More than 51\% of the businesses 
have been owned by $70 \%$ of the Saudi women and $42 \%$ women started their business themselves.

\subsection{Problem Statement}

The problem of unemployment in Saudi Arabian society is multi-dimensional because the factors of its existence and ways are linked to multiple variables. Some of these variables are connected to the social and cultural factors in society, while others are linked to educational system and its output, and third groups are connected to the economic system.

\subsection{Significance}

The importance of the study comes out from the significance of small scale economic business projects to Saudi national economy because these projects employ simple productivity techniques that are characterized by high labor intensity. Thereby, they create job opportunities that absorb a sizable portion of unemployed manpower and reduce the increasing demand for government jobs. Furthermore, it has been indicated that the proposed solutions to the problems of small scale economic business projects are major strengths for national economy. Small businesses provide employment opportunities for job seekers and; reduces the unemployment rates in the Kingdom of Saudi Arabia (Al-Qahtani, 1433 AH, 6).

\subsection{Objective}

Following objectives have been devised to explore the role of small businesses in the Kingdom of Saudi Arabia:

- To define the concept of unemployment, its types, its causes and its impact on society.

- To propose possible solutions for overcoming the problem of unemployment.

- To shed light on small -scale economic business projects (small businesses), their importance and role expected to play in alleviating the problem of unemployment.

- To highlight the problems that confront small-scale economic business projects (small businesses) in the Kingdom of Saudi Arabia.

\subsection{Research Questions}

Question 1: What are the causes of unemployment in a country?

Question 2: Does unemployment has certain negative consequences on society?

Question 3: Is unemployment linked to high population growth rates?

Question 4: Does provision of employment opportunities through small scale economic business projects (small businesses) lead to reduce unemployment phenomenon?

Question 5: What is the impact of the small scale economic business projects on the national economy?

\section{Theoretical Framework}

The most important feature of the third millennium is represented in the problems of growing unemployment in its various forms including escalating rate of poverty, destitution and social exclusion. The priorities of the international community are topped at different official and popular levels. The economic, social, and humanitarian dimensions have become a constant as well as disturbing concern for governments and countries as it eventually constitutes a continuous threat to peace, security and mankind. Additionally, the consequences of this phenomenon still stand as a stumbling block before achieving the goal of comprehensive and sustainable development (Dahlan, 2005).

Unemployment can be defined as the presence of individuals in a society who are able to work, and qualified for both required type and level. These individuals desire for it, seek and agree to accept it under the framework of prevailing wages, but they did not find it at a particular period of time (Abdul Wahab, 2005). Furthermore, unemployment is defined as the situation in which society did not use the labor force fully or optimally. Hence, the actual product of this community is less than potential product where an act leads to a low level of welfare of individuals to be reached (Abdul Wahab, 2005).

\subsection{The official Measure of Unemployment}

The unemployment rate is the division of the number of unemployed individuals by the total size of work force and multiplied by $100 \%$ (Jamei, 2008). The formula is as follows:

Unemployment rate $=($ number of unemployed individuals) divided by / (work force $) \times 100 \%$

The work force refers to all employed and unemployed capable individuals, who want to work under the prevailing wage. It is important to point out that the measurement of unemployment rate is a difficult measure in 
developing countries as compared to developed countries (Abdulwahab, 2005). The non-possession of official authorities for sound data is the major cause that can be taken as a measure for the unemployment size. This is due to the lack of unemployment benefits that motivate unemployed individuals to register themselves. Another reason for the measurement of unemployment rate is relied on the relative weight of the so-called hidden or black or parallel illegal economy, which is greater in developing countries as compared to developed countries. Relative weight cannot be neglected as the activities of this economy are not included in the official statistics. Furthermore, the lack of accurate statistics and data about the informal sector in developing countries is considered usually in urban sector including small projects and handy individuals.

\subsection{Types of Unemployment}

Appropriate identification of research participants is critical to the science and practice of psychology, particularly for generalizing the findings, making comparisons across replications, and using the evidence in research syntheses and secondary data analyses. If humans participated in the study, report the eligibility and exclusion criteria, including any restrictions based on demographic characteristics.

\subsubsection{Visible Unemployment}

Visible unemployment is emerged in the form of individuals who have not utilize their capabilities at the work places. These individuals are observed as the most widespread and common form of unemployment and; therefore, divided into two sub-types: compulsory unemployment and optional unemployment. Compulsory unemployment is the presence of individuals, who are able and willing to work, but they did not find it under the prevailing wage in the market. Compulsory unemployment can be represented in the form of individuals who are capable and willing to search for occupations that are appropriate as compared to their prior ones. Despite the fact that there are occupations that are appropriate in accordance to their qualifications and skills, but they did not acquire them. The main reason for this assertion is the unfamiliarity regarding particular occupation and departments. Similarly, structural unemployment refers to the occurrence of structural changes in the economy, leading to non-conformity of job opportunities available with the skills of workers seeking work.

Numerous causative agents have been defined that lead towards the structural unemployment. The modifications in demand structure are mainly focused in the structural unemployment, which eradicate the demand for manpower due to recession suffered by the economy. Moreover, these modifications are also observed towards the affected industries and emergence of demand for particular types of skills (Zaki, 1997). Technological development can lead to the creation and invention of new goods and products as such incidence will consequently lead to exposing workers involved in the production of old goods and products. The paucity of awareness for modern technology can create chances for unemployment as these technologies are advanced to develop goods and products without the assistance of mankind. Modifications in the labor force increases the percentage of inexperienced females and fresh graduates. This augmentation might be emerged due to the non-conformity of educational outputs with the labor market requirements.

Cyclical unemployment is linked to economic fluctuations or the so-called economic business cycle, as it surfaces in recession periods in which the aggregate demand for goods and services usually declines. The seasonal unemployment arises when demand for workers in certain seasons diminishes and it spreads mostly in dense populated developing countries that are largely dependent on agricultural activity. Therefore, the increment of manpower in this sector reflects a kind of seasonal unemployment due to the nature of agricultural activity.

\subsubsection{Disguised or Invisible Underemployment}

Invisible underemployment is revealed as the constituent of the surplus manpower having the excess of the actual need of the work. It is comprehensively appeared in the work to achieve consequent increase in the total product and with zero marginal productivity of up to zero. Disguised or invisible unemployment was found in the past at the agricultural sector of developing countries; however, it escalated due to the increase in government employment process.

\subsection{Unemployment Rates for the Years 2007-2012}

According to the survey conducted by the Central Department of Statistics and Information of the Kingdom of Saudi Arabia (2007-2012), the increase in the general unemployment is examined from the overall unemployment rate of the Saudi Arabia among both sexes, which has reached to $12.1 \%$ in 2012. Furthermore, the unemployment rate of Saudi males is reduced up to $6.1 \%$ in 2012. Similarly, increase in the Saudi females' unemployment rate by $(9.1 \%$ ) is reached at $35.7 \%$ in 2012 (compared to $26.6 \%$ in 2007). Furthermore, it was remarked that the total number of unemployed Saudis (male and female) rose in 2012 by (24.7\%) and the number of the unemployed individuals increased by 149 thousand $(149,000)$ to reach 603 thousand $(603,000)$ 
unemployed individuals (compared to 454 thousand $(454,000)$ in 2007). This was mainly resulted due to decline in both the percentage of total number of unemployed male Saudis by $(9.9 \%)$ and their number by 27 thousand $(27,000)$, to reach 244 thousand $(244,000)$. Increase in both the percentage of total number of unemployed Saudi females by $(49 \%)$ and their number by 176 thousand $(176,000)$ to reach 359 thousand $(359,000)$ was also the major reason for unemployment extent.

Table 1. Unemployed Saudis by Sex and Unemployment rates for the years (2007-2012)

\begin{tabular}{lllllll}
\hline \multicolumn{2}{l}{ Unemployed Individuals } & & \multicolumn{5}{l}{ Unemployment Rates } \\
\hline Year & Male & Female & Total No. & Male & Female & Total No. \\
\hline $\mathbf{2 0 0 7}$ & 271,007 & 182,987 & 453,994 & 8.0 & 26.6 & 11.2 \\
$\mathbf{2 0 0 8}$ & 239,170 & 177,180 & 416,350 & 6.8 & 26.9 & 10.0 \\
$\mathbf{2 0 0 9}$ & 248,162 & 200,385 & 448,547 & 6.9 & 28.4 & 10.5 \\
$\mathbf{2 0 1 1}$ & 282,930 & 302,797 & 585,727 & 7.4 & 33.4 & 12.4 \\
$\mathbf{2 0 1 2}$ & 243,983 & 358,870 & 602,853 & 6.1 & 35.73 & 12.1 \\
\hline
\end{tabular}

Source: Statistical Yearbook of 2012 (Chapter II, Part V, p. 18) Access date (06/29/2013) (http://portal.mol.gov.sa)

The Saudi Ministry of Labor has indicated that the unemployment rate in the Kingdom of Saudi Arabia escalated to $12.1 \%$ in 2012, and the highest percentage of unemployed Saudis holding bachelor's degrees were $49.4 \%$, followed by those holding secondary school certificates with $29.9 \%$.

\subsection{Solutions for Addressing the Problem of Unemployment in the Kingdom of Saudi Arabia}

Mankind has been encouraged to associate with the state to achieve sustainable development. The government has been focused to address the major dilemma of unemployment among youth category. Therefore, self-efforts and assistance have been escalated by government along with societal and governmental organizations such as Centennial (Centenary) Fund and Bab Riziq Jameel to help them establish their own economic small economic projects. These assistance add values to the national economy and provide new job opportunities. Small economic projects are considered among the solutions used by the Kingdom of Saudi Arabia in combating unemployment and in the absorption of the possible portion of the national workforce, which were not employed successfully by the Kingdom.

The Ministry of Labor and Employment in the Kingdom of Saudi Arabia has applied the Saudi employment strategy to achieve three general objectives including full employment of the labor force, a continuous increase in the contribution of national human resources and the productivity of the national labor. The launch of the Program for assistance of the Incentive has been developed in implementation to the Royal Decree No. A / 61 dated 13/04/1432 H. Furthermore, Human Resource Fund was able through adopting employment support programs to train 139,899 Saudi beneficiaries (male and female).

The launch of Program encourages companies, establishments, firms and factories to develop a new criteria for the employment of Saudi nationals under the Saudization process at the private sector enterprises and to reduce the number of unemployed individuals. In fact, in 1433 AH 459,400 Saudis were employed by the private sector enterprises. The Ministry of Labor and Employment in the Kingdom of Saudi Arabia has given particular attention to women's work, by adopting a number of measures that facilitate the employment of women and secure them for honorable work areas. The development of wage protection program guarantees the receipt of labors at the private sector for their wages and salaries through depositing them at their respective bank accounts. Thus, this process addressed the problems of illegal hidden employment.

\subsection{The Concept of Small Projects}

Abulfahm (2009) has mentioned concept of small projects by observing the volume standard of the capital invested in the project: This standard is comprised of the strategies, which distinguish the types of the small business. It is assumed that the small project did not intensively use capital but the determination of the capital of small project differs from one country to another. Small businesses are characterized by the reduction of the value of its products, and hence the value of its sales. This standard is considered an honest measure for the level of project activity. Furthermore, small businesses are known for the low value of their sales, link to the local markets and their inability to market their products in international markets. Similarly, different sales volume is classified from one country to another. Number of Employees Standard is the most common standard for the definition of small economic projects, as small businesses employ a limited number of workers. The Ministry of Finance and National Economy uses the number of employee's standard as the basic standard for determining the number of corporations or small businesses. In fact, $86.8 \%$ corporations or small businesses employ between (10-100) workers in various cities of the Kingdom of Saudi Arabia (Juhani, 2008). 


\subsection{Small Businesses and Their Role in Tackling Unemployment}

The increasing concern of the Kingdom of Saudi Arabia with increased small projects resulted to play a significant role in the development of the national economy and in the employment opportunities. In fact, the Kingdom of Saudi Arabia has commenced to encourage the establishment and running of such projects to contribute in the achievement of economic and social development in these countries. When complex atmosphere was created and the required funding was provided, these projects were given the right climate and funding in terms of promulgation of required laws and facilitation of the government's procedures.

The importance of small projects in the economic development is apparent that they directly contributes to the national income. These projects lead to increase the added values and contributes to the balance of payments via reducing the importation of goods. Furthermore, products and the application of the policy of substituting imports with locally produced goods and the development of the export sector of the state is examined through such projects. Furthermore, these small projects exploit raw materials available locally upon which many large industries depend. They also constitute an arena for the development of administrative, technical, and productive and marketing skills to open up a wide range for individual initiatives and self-employment (Al-Qahtani, 1433 $\mathrm{AH})$.

\subsection{The Current Status of Small-scale Projects in the Kingdom of Saudi Arabia}

The report of the Social Insurance Organization has indicated that the growth indicators in the businesses achieved high growth rates in recent years. This is confirmed by the fact that, the number of enterprises are subscribed to the Social Insurance system with the Social Insurance Organization, as the social security system emerged between 121,500 in $1426 \mathrm{AH}$ to 218,4000 in $1430 \mathrm{AH}$ with an average annual growth rate of $16 \%$. The economic activity of the small scale-economic projects (small businesses/establishments) in the Kingdom of Saudi Arabia has been confined to three activities; namely trade with $34.3 \%$, construction with $32.3 \%$ and transformational industries with $14.6 \%$, as indicated in the figure 1 below:

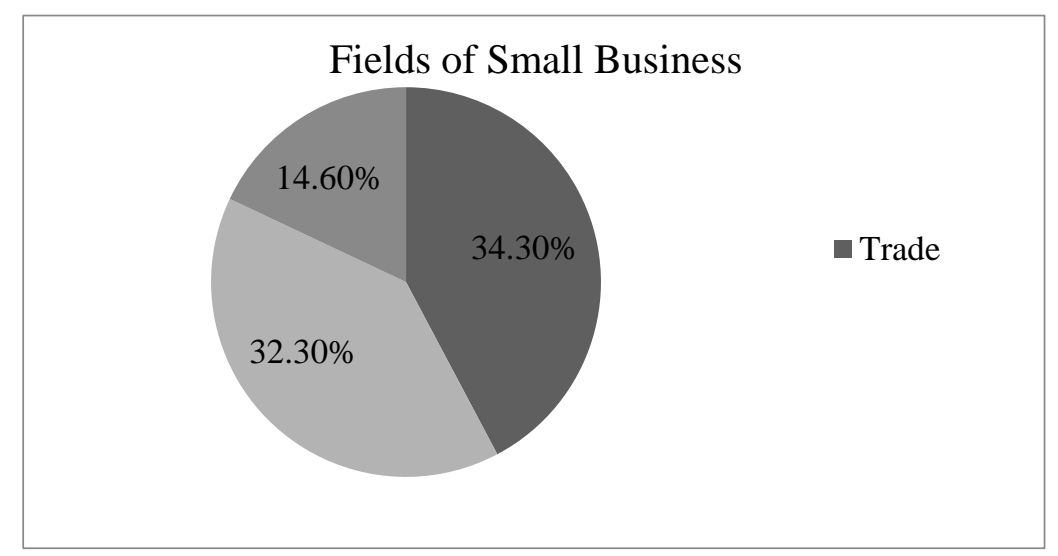

Figure 1. Areas of work of the small businesses in the Kingdom of Saudi Arabia

Source: Saudi Economic Journal, No. 39, p. 44

The classification of the small scale economic projects indicated that the percentage for 5 workers (employees) is $54.4 \%$ and firms employing 5 to 59 workers accounted about $41.8 \%$ and the remaining $3.8 \%$ occupied by enterprises with more than 60 workers, as shown in the figure 2. Based on the number of workers standard, it is clear that small enterprises in the Kingdom of Saudi Arabia accounted for $96 \%$. 


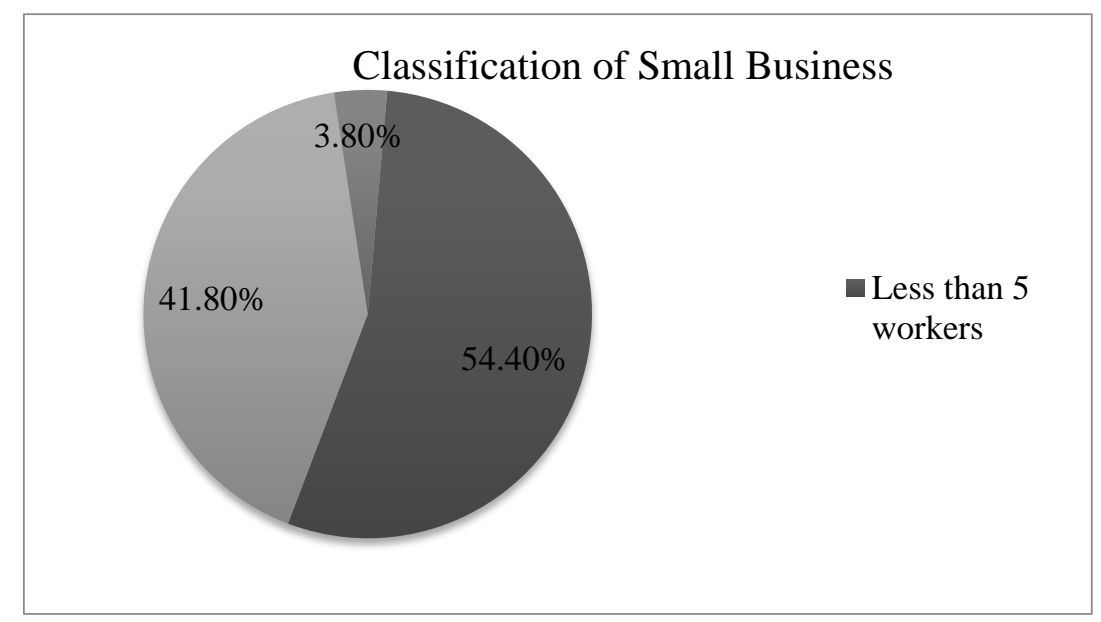

Figure 2. Classification of small and medium-scale economic projects (enterprises) based on the number of workers standard used in the Kingdom of Saudi Arabia.

Source: Saudi Economic Journal, No. 39, p. 44

\subsection{Social Importance of Small Projects}

The entrepreneurial culture and the establishment of small businesses directly affect the proprietors, children, work, and on their daily lives. The establishment of small projects improves their living conditions by raising their incomes, meeting their needs and to ensure stability for themselves and their families. This aspect will develop certain opportunities to express themselves and their abilities to achieve social cohesion among members of society through the relationships that are created among employees as well as to create a balanced relationship among the various segments of society. It is a fact that the opportunity will be available to all those who work, persevere, strive and aspire for the best.

\subsection{Economic Importance of Small Projects}

The economic significance of the small businesses in the Kingdom of Saudi Arabia can rely on the intensity of the work factor more than its dependence on the intensity capital factor. These projects are dependent on the commencement of unskilled workforce while it shifts into the skilled one, because it gained required technical experience through working in these projects. Furthermore, these small projects have supplied the long run major projects with technical trained manpower.

The small enterprises in the Kingdom of Saudi Arabia constitute $90 \%$ of the total number of projects functioning in the country; and absorb at least $35 \%$ of the total workforce. Furthermore, individual establishments make up 94.8\% of the total number of commercial registries issued so far (Shalaby, 2008, 228).

During the period 2005-2012, an increase in the tendency of youth for establishing their private projects as well as spread the awareness towards the significance of this sector was indicated. The number of small projects funded in 2010 was (2960), 4880 in 2012 with an increment rate of (39.34\%). Furthermore, the number of Saudi individuals working in small enterprises reached in 2010 (690) was compared with number of small enterprises in 2012, which reached (750), with an increasing rate of (8\%).

Table 2. Number of small enterprises and the number of Saudi employees joining them

\begin{tabular}{lll}
\hline Year & No. of Small Projects & No. of Saudis joining small projects \\
\hline $\mathbf{2 0 0 5}$ & 25 & 12 \\
$\mathbf{2 0 0 6}$ & 417 & 60 \\
$\mathbf{2 0 0 7}$ & 540 & 263 \\
$\mathbf{2 0 0 8}$ & 1040 & 300 \\
$\mathbf{2 0 0 9}$ & 2000 & 648 \\
$\mathbf{2 0 1 0}$ & $2960^{*}$ & 690 \\
$\mathbf{2 0 1 1}$ & $3920^{*}$ & 720 \\
$\mathbf{2 0 1 2}$ & $4880^{*}$ & $750^{*}$ \\
\hline
\end{tabular}

Source: Centennial Fund for the years (2005-2012) (* This data is only estimated figures, not actual ones)

The increase and diversification of Gross Domestic Product (GDP) increase the size and diversity by effective means of expanding and diversifying the productive base as they meet the needs of the local market for commodities or services. Furthermore, such projects seek to take advantage of the available local resources, an act that may lead to the increment and diversification of GDP and; thus, elevation of the economic growth rate. 
Furthermore, small businesses in the Kingdom of Saudi Arabia contributed 28.7\% of the GDP generated by the private sector (excluding oil) (Shalabi, 2004). The Ninth Development Plan (2010-2015) has allocated its thirteen objectives for the development of corporations and small projects as well as for the creation of development of frameworks necessary for its patronage and organization to increase the proportion to the gross domestic product (GDP) (Saudi Economic Journal, 1432 AH).

Balanced regional development is achieved due to their small size and the possibility of their spread in most geographical areas in the Kingdom of Saudi Arabia. The specialized abilities provided in different areas (industrial, agricultural and service) by the small-scale projects (small businesses) develops rural communities and; therefore, reduce migration of individuals to the most developed cities in the Kingdom of Saudi Arabia.

\subsection{Role of Small Businesses in Economic Development}

Small businesses have endowed catalytic reimbursements to the economic growth. The contribution of small businesses is observed on the national output as well as to the local populace in spite of the consumption and profit they produce. Within the new global economy, manufacturing is perceived less important while services have dominated its existence, which consequently played a vital role for small businesses in dominating service sectors. However, the contribution of small businesses is perceived by several economists in escalating the economic development. It is being argued, that small businesses might innovate, customize products and shift rapidly to fluctuate situations. These businesses have less unionized workforces and ordered management systems to strengthen the economy (Decker et al., 2014). Economic activity by small businesses is significantly considerable for accomplishing economic progression. Furthermore, small businesses became more dominant by adopting tangible resources.

\subsection{Small Businesses and Sustainability}

Small businesses maintain the technological lead in the international marketplace as well as drive the economy into new dynamics. Indeed, small firms are essential in determining the fiscal conditions of the country and equivalently significant in playing role in the health of the local populace. Specific and general environmental analysis is being the most dominant factor influencing consequently on the external environment of a system or an organization (Williams \& Schaefer, 2013). Furthermore, the concentrations are faced in terms of sustainability and sustainable development to identify the wider-ranging practices. Financial limitations and costs are the major factors through which the existence of small businesses is restricted towards environmental sustainability. Similarly, it is being notified that paucity of financial awareness and employee management obstructed the adoption of sustainability practices (Loorbach \& Wijsman, 2013).

Strong pressures from external stakeholders are being the cause for small firms to react towards sustainability; however, large businesses were mostly associated to entail in preventive sustainability practices. Numerous studies have observed that small businesses are largely ignorant regarding their environmental regulation, environmental influence and assessment tools constructed to enhance their environmental performance. However, the involvement of small businesses towards sustainability endows them with initial reimbursements and strength. These firms have the potential to utilize innovative strategies in their business practices. There is a need for small businesses to adopt and implement sustainable business practices (Roxas \& Coetzer, 2012).

\subsection{Environmental Conservation and Sustainable Development}

Sustainable development is devised to sustain and attain the dimensions in social, political, environmental and economic spheres. The sustainable development has searched for the primacy of social, political and environmental dimensions through environmental conservation. Environmental conservation is the enduring presence of mankind, which depends on the preservation of the biosphere diversity (Ciegis, Ramanauskiene \& Martinkus, 2015). Furthermore, the mankind cannot depend on other natural resources and cannot survive without appropriate air and water provisions. The welfare and existence of mankind is endangered unless the biosphere is adequately conserved. The environment conservation is largely influenced through economic systems; whereas, operations of economic systems are affected by social and political systems. Governance and property rights have been shifted time to time and considered to be the dominant aspect for performance of society and environment conservation (Hobbs \& Saunders, 2012).

\section{Methodology}

Quantitative approach has been employed along with descriptive method to elucidate the concept of unemployment, and the factors influencing it as well as its types and consequences on society. The descriptive method was also utilized to examine the role of small scale economic business projects. 


\subsection{Data Collection}

The data for small-scale economic businesses was also retrieved through general statistics directorate of the Kingdom of Saudi Arabia. Unemployment - population at working age -small-scale economic projects (small businesses) - small projects funding were defined as the study variables. The data was retrieved through centennial fund during the years 2005-2013 to support small-scale economic business projects.

\subsection{Data Analysis}

The data retrieved from the general statistics directorate of the Kingdom of Saudi Arabia was analyzed to test whether there is significant correlation between the variable dependent on unemployment rate and independent variables (the total number of population and the number of small projects and the amount of funding available). Therefore, Multiple Regression Analysis (MRA) has been applied on the collected information using Statistical Package for Social Sciences (SPSS). The Multiple Regression Analysis have advantages that it can incorporate fairly the general functional forms of the variables. It allows more flexibility than the linear regression model. It is the most widely used empirical analysis in the social sciences and other fields. MRA technique allows functional form of relationships between the variables (Stanley \& Doucouliagos, 2012; Cohen, 1983).

\section{Results}

The findings of the regression analysis have revealed that number of small projects significantly $(\mathrm{p}=0.051)$ influenced the unemployment rate in Saudi Arabia. Furthermore, there is a statistically significant $(\mathrm{p}=0.097)$ impact of population on the unemployment rate in Saudi Arabia. However, amount of funding available $(\mathrm{p}=0.451)$ is statistically insignificant on the dependent variable. MRA technique has shown the results clearly by presenting the impact of multiple independent variables on dependent variables as shown in the following results.

Table 3. Coefficients of independent variables

\begin{tabular}{|c|c|c|c|c|c|}
\hline \multirow[t]{2}{*}{ Model } & \multicolumn{2}{|c|}{ Unstandardized coefficients } & \multirow{2}{*}{$\begin{array}{l}\begin{array}{l}\text { standardized } \\
\text { coefficients }\end{array} \\
\text { Beta } \\
\end{array}$} & \multirow{2}{*}{$\mathbf{t}$} & \multirow{2}{*}{ Sig. } \\
\hline & $\mathrm{B}$ & Std. Error & & & \\
\hline 1(constant) & 49.119 & 17.815 & -- & 2.757 & 0.40 \\
\hline Population & -2.119 & 1.039 & -3.121 & -2.040 & 0.097 \\
\hline No. of small projects & 0.001 & 0.001 & 3.988 & 2.550 & 0.051 \\
\hline Amount of funding available & -0.008 & 0.009 & -0.514 & -.818 & 0.451 \\
\hline
\end{tabular}

$\mathrm{Y}=\alpha+\beta_{1} \mathrm{x}_{1}-\beta_{2} \mathrm{x}_{2}-\beta_{3} \mathrm{x}_{3}+\mathrm{e}$

Whereas,

$\mathrm{Y}=$ the unemployment rate in Saudi Arabia

$\alpha=$ constant

$\mathrm{X}_{1}=$ population

$\mathrm{X}_{2}=$ the number of projects or small businesses

$\mathrm{X}_{3}=$ the amount of funding available for small businesses

$\mathrm{E}=$ random error or residuum

Thus, the equation is as follows:

$\mathrm{Y}=49.119-2.119 \mathrm{X} 1+\mathrm{x} 0.001 \times 2-0.0083 \times 0.62199$

Table 4. Relationship between the unemployment rate and the number of population

\begin{tabular}{llllll}
\hline Model & B & Std. Error & Beta & T & Sig. \\
\hline Population & -2.119 & 1.039 & -3.121 & -2.040 & 0.097 \\
\hline
\end{tabular}

The value of "population" coefficient in the table above was (-2.119). This negative sign indicated the existence of an inverse relationship between the unemployment rate and the number of people as the population increase leads to lower unemployment and vice versa. Furthermore, the value of possible significance in Table (4) was (0.097); and this was greater than the level of significance (0.05). Thus, the findings indicated that there is no statistically significant difference (relation) between the dependent variable pertaining to unemployment rate and the independent variable concerning population. 
Table 5. Relationship between the unemployment rate and the number of small projects

\begin{tabular}{llllll}
\hline Model & B & Std.Error & Beta & T & Sig. \\
\hline Number of small projects & 0.001 & 0.001 & 3.988 & 2.550 & 0.051 \\
\hline
\end{tabular}

The value of coefficient of the "number of small projects" reached (0.001) and positive sign is indicative of the existence of direct relation between the unemployment rate and the number of small projects, as an increase in the number of small projects leads to the increase of the unemployment rate and vice versa. Moreover, the value of possible significance reached (0.097) in Table (5) and it is greater than the level of significance (0.05). Thus, it is accepted that there is no statistically significant relation between the dependent variable pertaining to unemployment rate and the independent variable concerning the number of small projects.

Table 6. Relationship between the unemployment rate and the amount of funding available

\begin{tabular}{llllll}
\hline Model & B & Std.Error & Beta & T & Sig. \\
\hline Amount of funding available & -.008 & 0.009 & -0.514 & -0.818 & 0.451 \\
\hline
\end{tabular}

The value of coefficient of the "amount of funding available" reached (0.008) and negative sign is indicative of the existence of a reverse relation between the unemployment rate and amount of funding available, as an increase in the amount of funding available leads to the decrease of the unemployment rate and vice versa. Moreover, the value of possible significance reached (0.451) in Table (6) and it is greater than the level of significance (0.05). Thus, it is accepted that there is no statistically significant relation between the dependent variable pertaining to unemployment rate and the independent variable concerning the amount of funding available.

It is observed from the results that data was not in conformity with the study assumptions. Therefore, it is assumed that there was a direct relationship between the unemployment rate and the number of the population. There was an inverse relationship between the unemployment rate and both the number of small projects and the amount of funding available. This is due to the lack of sufficient available data because of both the short life of the Centennial Fund and shortage of time series available. Therefore, as longer the time series data, the more reliable are the accurate results.

Table 7. Model Summary

\begin{tabular}{llllllllllll}
\hline Model & $\mathbf{R}$ & $\begin{array}{l}\mathbf{R} \\
\text { Square }\end{array}$ & $\begin{array}{l}\text { Adjusted } \\
\text { R Square }\end{array}$ & $\begin{array}{l}\text { Std. } \\
\text { Error of } \\
\text { the } \\
\text { Estimate }\end{array}$ & \begin{tabular}{l} 
Change Statistics \\
\cline { 5 - 10 }
\end{tabular} & $\begin{array}{l}\text { R square } \\
\text { change }\end{array}$ & $\begin{array}{l}\text { S } \\
\text { change }\end{array}$ & Df1 & Df2 & $\begin{array}{l}\text { Sig. } \\
\text { Change }\end{array}$ & $\begin{array}{l}\text { Durbin- } \\
\text { Watson }\end{array}$ \\
\hline $\mathbf{1}$ & 0.768 & 0.618 & 0.388 & 0.6220 & 0.618 & 2.693 & 3 & 5 & 50.157 & 2.259 \\
\hline
\end{tabular}

a. Predictors: (constant), the amount of funding available, population, number of small projects

b. Dependent Variable: Unemployment rate

It is clear that the value of the overall correlation coefficient is $\mathrm{R}=0.786$. The correlation coefficient is revealed for the independent variables (the number of the population, the number of small projects and the amount of funding available) and the dependent variable (the unemployment rate). It is indicated that the existence of a direct and strong correlation between the dependent and independent variables is closer to one (0.786). It is noted that the value of the determination coefficient $\mathrm{R}$ square is equal to 0.618 ; and the value of the adjusted determination coefficient is 0.388 . The coefficient of determination is referred as the amount of explained variance by the regression model, which makes it beneficial as a measure of success of predicting (Nagelkerke, 1991).

The dependent variable from the independent variables.

Table 8. Analysis of Variance (ANOVA)

\begin{tabular}{llllll}
\hline Model & Sum of Squares & df & Mean Square & F & Sig. \\
\hline Regression & 3.126 & 3 & 1.042 & 2.693 & 0.157 \\
Residual & 1.934 & 5 & 0.387 & & \\
Total & 5.060 & 8 & & & \\
\hline
\end{tabular}

a- Predictors: (constant), the amount of funding available, population, number of small projects

b- Dependent Variable: Unemployment rate

The value of possible significance reached $(0.157)$ and it is greater than the value of significance $(0.05)$. Thus, the relation is significant, which explains a significant percentage in the dependent variable (unemployment rate). 


\section{Discussion}

The role of small businesses in the alleviation of unemployment as applied in the Kingdom of Saudi Arabia for the years 2007-2012 is revealed through the time-series regression. The role played by the small businesses is emerged in the economies internationally. Therefore, these small businesses have proved their ability to achieve a number of social and economic objectives, and that they also provided job opportunities for those seeking employment. Governmental and private bodies, such as Centennial Fund, Abdul Latif Jameel Fund for Community Services and the Human Resources Development Fund and others have focused on encouraging young people to establish small businesses to secure solutions to unemployment.

The data of variables concerning this study was obtained from both the Centennial Fund on the Support Small Projects and the Department of Statistics, Saudi Arabia. The paucity of time series data did not provide appropriate results in accordance to the hypothesis. One of the most important results of the study was the presence of a strong direct correlation relationship between the dependent variable (the unemployment rate) and independent variables (the number of the population and the number of small projects and the amount of available funding). Therefore, the value of correlation coefficient $\mathrm{R}$ and the value of the determination coefficient $\mathrm{R}^{2}$ indicated that the independent variables affect the dependent variable by $62 \%$. There is a direct relationship between the unemployment rate and the number of small projects; whereas, an inverse relationship was revealed between the unemployment rate and both the amount of funding available and the number of population.

The developing countries have worked hard to embark effective strategies that support the initiation of small businesses that would help to meet the needs for economic growth of the country. For starting up a successful business, the entrepreneurs need training, empowerment of the minority groups, and most importantly capital. There is a need for efficient business policies for the economic improvements of the country to cope up with the changes in global economy and technological advancement. The Saudi government favored the promotion of business programs, especially it facilitates the establishment of small business which have low financial capacity (Salem, 2014). In Saudi Arabia, the year 2010 has been marked as the launch of new entrepreneurship innovations and efforts to start small scale business. It has been indicated through economic research that in the developing countries the small scale business make up approximately $92 \%$ of overall businesses. Moreover, these small scale businesses offer employment to approximately $80 \%$ of the population residing in those countries (Ellison et al., 2003). Therefore, it is important for the developing countries to nurture the generation of leaders, innovators, and businessmen for effective growth in the economy of the country.

Small businesses are apprehending the existence of foreign markets and foreign sources by means of internet for augmenting success and growth. Numerous business opportunities have been developed as majority of the large businesses eradicated their activities to minimize costs. Small businesses facilitated progression of society by desirable private investment back into lagging regions and extent the incentives of economic growth to individuals (Gronum, Verreynne \& Kastelle, 2012). The existence of small businesses have provided a mechanism to augment the interaction among markets and organizations. The association of small firms is apparently linked with the vendors and customers. The connectivity is escalating the progression of dynamic organizational associations between entities. Tax incentives and other inducements are focused by small business sectors towards the unemployment and economic development.

Sustainable development is largely associated with the existence of large businesses; whereas, it appears difficult for small businesses to adopt these practices. The major cause for this assertion is the practices, which are structured for large businesses on the basis of revenues, budgets and number of workforce. The contribution of small businesses towards sustainability is observed through internal and external attributes including ownership structure, business culture and employees knowledge despite of these barriers. Therefore, small businesses have perceived sustainability and adopted sustainability business practices as a moral obligation to local populace (Keskin, Diehl \& Molenaar, 2013). It has been examined that instigation of sustainability practices endowed small businesses to eradicate costs. Operational measures are the most dominant initiative that focus comprehensively on the environmental dimension of business practices. Imperative and positive public relations can be observed through sustainable business practices. These reimbursements can differentiate small businesses from its competitors and can be appeared as the source of market opportunities and competitive advantages. Increased financial profile might allow small businesses to more quickly adapt dynamic opportunities (Carroll \& Buchholtz, 2014).

Economic and environmental outcomes can be emerged through the inadequate strategies of property rights including the use of environment. The governance is regarded as a constituent for sustainable development, 
which stresses the importance of local community's empowerment. Expansion in market systems and property rights can extend the achievement of sustainable development and its environmental conservation (Sen, 2013). It is being observed that advancement of technologies provides determined environmental consequences, to accomplish sustainable development and environmental conservation. Resources are the fundamental asset in the economic growth and endow two vital principles: environmental principles and raw materials for production of goods and services. The problem of reduction notifies a significant role in the implementation of renewable and non-renewable resources. Environmental resources might be degraded through rendered useless and pollution (García-Amado, Pérez \& García, 2013).

\section{Conclusion}

It has been concluded that a special body should be created to support and develop small enterprises, because it is intended to coordinate between projects and government agencies. Furthermore, a database containing all the data should be provided to concern the proprietors of the small businesses. The function of the centennial fund has been emphasized for supporting small projects and to enhance its mechanisms as an independent non-profit institution. Furthermore, an appropriate environment must be provided to small businesses to embrace and construct their potentials. Procedural restrictions should be overwhelmed, which eradicated the guarantees needed by the lending institutions from the owners of small business. It has been suggested that training programs should be developed to enhance technical and managerial skills of young people in a manner that copes with the needs of the labor market.

\subsection{Limitations}

Only the small scaled business has been considered and the data gathered was specifically from the general statistics, directorate of the Kingdom of Saudi Arabia, during the years 2005-2013. Limited resources were considered as another limitation for the study, which have somehow affected the nature of study. Similarly, limited time frame was another limitation for the study.

\section{Acknowledgments}

The author is very thankful to all the associated personnel in any reference that contributed for the purpose of this research. Further, this research holds no conflict of interest and is not funded through any source.

\section{References}

Abu Al-faham, Z. (2009). The role of small businesses in the fight against poverty and unemployment in the Arab world (first edition, Abu Dhabi Dar Culture for Publishing and Distribution: 2009).

Al-Khatib, J., Dant, R. P., \& Vitell, S. J. (2015). Marketing and Economic Development: the Saudi Arabian Experience. In Proceedings of the 1989 Academy of Marketing Science (AMS) Annual Conference (pp. 659-664). Springer International Publishing. https://doi.org/10.1007/978-3-319-17055-8_134

Al-Qahtani, Reem, A. Estimate the request function for small and medium enterprises against finance by specialized lending institutions in Saudi Arabia, Master Thesis (not published), King Abdul Aziz University, Jeddah function (1433 AH).

Arab business: the high unemployment rate in Saudi Arabia to 12.1\% in 2012 (the date of entry 9/8 / 2013): arabic.arabianbusiness.com/society/politics-economic.www

Asharqal-awsatelectronic Newspaper: Practical solutions for solving the problem of unemployment, (the date of entry, 17/6/2013), www.alsharq.net.sa

Carroll, A. B., \& Buchholtz, A. K. (2014). Business and society: Ethics, sustainability, and stakeholder management. Nelson Education.

Ciegis, R., Ramanauskiene, J., \& Martinkus, B. (2015). The concept of sustainable development and its use for sustainability scenarios. Engineering Economics, 62(2).

Cohen, J. (1983). The cost of dichotomization. Applied psychological measurement, 7(3), 249-253. https://doi.org/10.1177/014662168300700301

Dahlan, A. S. (2005). small enterprises and their role in addressing poverty and unemployment (Swiss Arab Center for Research on Employment and Human Rights at Work, 2005).

Decker, R., Haltiwanger, J., Jarmin, R., \& Miranda, J. (2013). The Secular Decline in Business Dynamism in the US. Manuscript, University of Maryland.

Ellison, C., Hummer, R., \& Sakamoto, A. (2003). Business incubation in inner-city emerging markets as an 
economic development tool.

Frazer, L. (2012). The effect of internal control on the operating activities of small restaurants. Journal of Business \& Economics Research, 10(6), 361. https://doi.org/10.19030/jber.v10i6.7027

García-Amado, L. R., Pérez, M. R. \& García, S. B. (2013). Motivation for conservation: Assessing integrated conservation and development projects and payments for environmental services in La Sepultura Biosphere Reserve, Chiapas, Mexico. Ecological Economics, 89, 92-100. https://doi.org/10.1016/j.ecolecon.2013.02.002

Gronum, S., Verreynne, M. L., \& Kastelle, T. (2012). The role of networks in small and medium-sized enterprise innovation and firm performance. Journal of Small Business Management, 50(2), 257-282. https://doi.org/10.1111/j.1540-627X.2012.00353.x

Hobbs, R. J., \& Saunders, D. (Eds.). (2012). Reintegrating fragmented landscapes: towards sustainable production and nature conservation. Springer Science \& Business Media.

Jamei, M. N. (2008). Unemployment: a time bomb - Its Deciphering and Talk with young people, (Alexandria, Dar Al-Fath, 2008).

Juhani, A. C. (2008). Success factors of small enterprises supported by the private sector in Saudi Arabia: Evaluate the experience of the Abdul LatifJameel Fund for the support small enterprises, Master's Degree dissertation which was not published) King Abdul Aziz University, Jeddah (2008).

Keskin, D., Diehl, J. C., \& Molenaar, N. (2013). Innovation process of new ventures driven by sustainability. Journal of Cleaner Production, 45, 50-60. https://doi.org/10.1016/j.jclepro.2012.05.012

Link, A. N., \& Scott, J. T. (2012). Employment growth from the small business innovation research program. Small Business Economics, 39(2), 265-287. https://doi.org/10.1007/s11187-010-9303-6

Loorbach, D., \& Wijsman, K. (2013). Business transition management: exploring a new role for business in sustainability transitions. Journal of Cleaner Production, 45, 20-28. https://doi.org/10.1016/j.jclepro.2012.11.002

Nagelkerke, N. J. (1991). A note on a general definition of the coefficient of determination. Biometrika, 78(3), 691-692. https://doi.org/10.1093/biomet/78.3.691

Naja', A. A. W. (2005). The problem of unemployment and the impact of the economic reform program on it. An analytical Applied study (Alexandria, University House, 2005).

Official site of the Centennial Fund, the access date (9/7/2013), www.tcf.org.sa

Roxas, B., \& Coetzer, A. (2012). Institutional environment, managerial attitudes and environmental sustainability orientation of small firms. Journal of Business Ethics, 111(4), 461-476. https://doi.org/10.1007/s10551-012-1211-z

Salem, M. I. (2014). The role of business incubators in the economic development of Saudi Arabia. The International Business \& Economics Research Journal, 13(4), 853. https://doi.org/10.19030/iber.v13i4.8694

Saudi Economic Journal: Economy and small- and medium-sized enterprises, No. 39 (Spring 1432).

Sen, A. (2013). The ends and means of sustainability. Journal of Human Development and Capabilities, 14(1), 6-20. https://doi.org/10.1080/19452829.2012.747492

Shalabi, N. M. (2004). The role of incubators of small projects in the support the Arab Creativity. Journal of Economic Prospects, 97.

Solomon, G. T., Bryant, A., May, K., \& Perry, V. (2013). Survival of the fittest: Technical assistance, survival and growth of small businesses and implications for public policy. Technovation, 33(8), 292-301. https://doi.org/10.1016/j.technovation.2013.06.002

Stanley, T. D., \& Doucouliagos, H. (2012). Meta-regression analysis in economics and business (Vol. 5). Routledge.

The Ministry of Labour: Statistical Yearbook of 2012 (the date of ACCESS 29 / 6/2013), http://portal.mol.gov.sa

Welsh, D. H., Memili, E., Kaciak, E., \& Al Sadoon, A. (2014). Saudi women entrepreneurs: a growing economic segment. Journal of Business Research, 67(5), 758-762. https://doi.org/10.1016/j.jbusres.2013.11.040

Williams, S., \& Schaefer, A. (2013). Small and medium-sized enterprises and sustainability: Managers' values 
and engagement with environmental and climate change issues. Business Strategy and the Environment, 22(3), 173-186. https://doi.org/10.1002/bse.1740

Zaki, R. (1997). The Political Economy of unemployment (Kuwait, the world of knowledge, 1997).

\section{Copyrights}

Copyright for this article is retained by the author(s), with first publication rights granted to the journal.

This is an open-access article distributed under the terms and conditions of the Creative Commons Attribution license (http://creativecommons.org/licenses/by/4.0/). 